\title{
Salvage radiotherapy for recurrent hypopharyngeal and laryngeal squamous cell carcinoma (SCC) after first-line treatment with surgery alone: a 10-year single-centre experience
}

Sati Akbaba ${ }^{1,2,3}$, Thomas Held ${ }^{1,2}$, Kristin Lang ${ }^{1,2}$, Juliane Hoerner-Rieber ${ }^{1,2,3}$, Karim Zaoui ${ }^{4}$, Tobias Forster ${ }^{1,2}$, Stefan Rieken ${ }^{1,2,3}$, Peter Plinkert ${ }^{4}$, Juergen Debus ${ }^{1,2,3}$ and Sebastian Adeberg ${ }^{1,2,3^{*}}$

\begin{abstract}
Purpose: Salvage surgery of recurrent hypopharyngeal and laryngeal squamous cell carcinoma (SCC) results in limited local control and survival rates. As a result of recent technological progress, radiotherapy (RT) has become a valuable, potentially curative therapeutic option. Thus, we aimed to determine prognostic factors for survival outcome in order to optimize patient selection for salvage radiotherapy after failure of first-line treatment with surgery alone in this special patient cohort.

Methods: Seventy-five patients ( $85 \%$ male, median age of 64 years) underwent salvage RT in a secondary setting for recurrent hypopharyngeal or laryngeal SCC after prior surgery alone between 2007 and 2017. On average, patients were treated with one prior surgery (range 1-4 surgeries). Median time between surgery and salvage RT was 7 months (range 1-47 months) for initially advanced tumors (T3/4, N+, extracapsular spread) and 18 months (range 5-333 months) for initially early stage tumors. The majority of patients received concomitant chemotherapy ( $n=48 ; 64 \%)$ or other kind of systemic treatment concurrent to radiotherapy $(n=10 ; 13 \%)$.

Results: Median follow-up was 41 months (range 3-120 months). Overall, fifteen patients were diagnosed with local failure (all were in-field) at last follow-up (20\%). Median time to recurrence was 35 months (range 3-120 months) and 3-year local progression-free survival (LPFS) was 75\%, respectively. Dose-escalated RT with 70.4 Gy applied in 2. 1 Gy or 2.2 Gy fractions corresponding an EQD2 > 70 Gy $(p=0.032)$ and the use of concomitant cisplatin weekly chemotherapy $(p=0.006)$ had a significant positive impact on LPFS. 3-year OS and DPFS were 76 and 85\%, respectively. No toxicity-related deaths occurred. Reported grade $>3$ side effects were rare $(n=4 / 70,6 \%)$.

(Continued on next page)
\end{abstract}

\footnotetext{
* Correspondence: sebastian.adeberg@med.uni-heidelberg.de

The current manuscript was presented in part as poster on the annual meeting of German Radiation Oncologists on June 22, 2018 in Leipzig (DEGRO).

${ }^{1}$ Department of Radiation Oncology, University Hospital Heidelberg, Im Neuenheimer Feld 400, 69120 Heidelberg, Germany

${ }^{2}$ Heidelberg Institute for Radiation Oncology (HIRO), National Center for Radiation Research in Oncology (NCRO), Im Neuenheimer Feld 400, 69120 Heidelberg, Germany

Full list of author information is available at the end of the article
}

(c) The Author(s). 2019 Open Access This article is distributed under the terms of the Creative Commons Attribution 4.0 International License (http://creativecommons.org/licenses/by/4.0/), which permits unrestricted use, distribution, and reproduction in any medium, provided you give appropriate credit to the original author(s) and the source, provide a link to the Creative Commons license, and indicate if changes were made. The Creative Commons Public Domain Dedication waiver (http://creativecommons.org/publicdomain/zero/1.0/) applies to the data made available in this article, unless otherwise stated. 
(Continued from previous page)

Conclusion: Salvage radiotherapy resulted in excellent local control rates while radiation dose and the use of cisplatin weekly chemotherapy were identified as prognostic factors for LPFS. Nevertheless, patient selection for curative salvage treatment remains challenging.

Keywords: Squamous cell carcinoma, Recurrent hypopharynx and larynx carcinoma, Salvage radiotherapy, Function preservation

\section{Background}

Squamous cell carcinoma (SCC) of the larynx and hypopharynx is the most common tumor in the head and neck region, mainly observed in males over 50 years. Especially glottic larynx carcinomas are mostly diagnosed in early stages due to the disorder of essential laryngeal and hypopharyngeal functions presenting with initial symptoms, i.e. hoarseness, swallowing difficulties or dyspnea, resulting in significant reduced patient's satisfaction and quality of life [1-3]. Therefore, besides achieving optimum local control, preservation of phonatory and swallowing function gain in importance. The role of chemoradiotherapy (CRT) in the organ-preserving treatment of hypopharyngeal and laryngeal malignancies was established by two important landmark trials, showing equal survival rates compared with surgery and a high rate of larynx-preservation in twothirds of the patients $[4,5]$. Over the last two decades, CRT is increasingly considered as a valuable alternative to total laryngectomy for advanced tumors. Nowadays, total laryngectomy is mostly used in highly selected patients with advanced diseases or reserved as salvage surgery in case of treatment failure after primary CRT. In the current literature, poor prognosis is reported for patients who were treated with salvage surgery after radiotherapy failure in several studies [6, 7]. However, data concerning outcome of salvage CRT after failed first-line surgical treatment are still missing. The aim of this retrospective analysis is to assess clinical outcome in patients with recurrent hypopharyngeal and laryngeal SCC after first-line treatment with surgery alone, who received second-line RT in potentially curative intention and to determine prognostic factors for survival outcome to optimize patient selection for salvage radiotherapy.

\section{Materials and methods \\ Evaluation}

Seventy-five patients with laryngeal or hypopharyngeal SCC treated for recurrence after prior surgery at the Department of Radiation Oncology of the University Hospital Heidelberg between 2007 and 2017 were identified retrospectively and patient's records were analysed regarding local progression-free survival (LPFS), overall survival (OS) and distant progression-free survival (DPFS). Additionally, potential prognostic factors were assessed and calculated for local control (LC), OS and DPFS.
Follow-up was performed with magnetic resonance imaging (MRI) or computed tomography (CT) 6 weeks after completion of therapy, at three-month intervals during the first 2 years after treatment, every 6 months during the third year after treatment and then, once a year. Yearly CT scans of the chest and abdominal ultrasound were performed to identify distant relapse.

Acute and late toxicity were assessed according to the Common Terminology Criteria for Adverse Events version 4.03 (CTCAE v4.03) and tumor response to the current Response Evaluation Criteria in Solid Tumors (RECIST) [8, 9]. TNM (tumor, nodal, metastasis) stage was assessed and adjusted to the eight edition of the TNM classification system [10].

Survival data were calculated from first diagnosis to the date of last follow-up, death or progression by using Kaplan-Meier estimates (IBM SPSS Statistics version 24). OS was calculated from the first diagnosis up to the last follow-up or death. LPFS and DPFS were considered as the time period between first diagnosis and occurrence of local progression, distant progression or death. LC was calculated from first day of treatment to last follow-up or local progression. Univariate analysis to identify potential prognostic factors for survival outcome were performed using the log-rank test. For multivariate analysis, the cox regression model was used. All tests were 2-tailed and the significance level was defined as $\alpha<0.05$.

\section{Patient characteristics}

All patients received RT in a secondary setting for recurrence after first-line treatment with surgery alone (median number of operations 1 , range 1-4). Patients who received a prior radiation treatment were excluded from the study. Initially, postoperative RT $(n=13,17 \%)$ for UICC stage III/IV or CRT $(n=22,29 \%)$ for incomplete resection margin $(n=11,15 \%)$, lymph node metastases with extracapsular spread (ECS; $n=9,12 \%)$ or both $(n=2,3 \%)$ was obligatory in overall $47 \%$ of the patients but was declined from the patient. Therefore, two treatment groups were differed within the study population; early stage patients without an initial indication for postoperative RT ( $n=40$, 53\%) and patients with advanced tumors who declined postoperative RT after first-line surgery $(n=35,47 \%)$. Prior total laryngectomy was performed in $24 \%$ of the 
patients $(n=18)$, prior unilateral neck dissection (ND) in $9 \%$ of the patients $(n=7)$ and bilateral ND in $35 \%$ of the patients $(n=26)$. In $79 \%$, lymph node metastases could be identified ( $\mathrm{n}=26)$, in 11/26 patients with ECS (for detailed treatment characteristics please see Table 2).

The majority of the patients were male $(n=64,85 \%)$ and older than 60 years $(n=45,60 \%)$ at RT initiation (median age of 64 years, range $46-83$ years). The most common initial tumor sites were the glottic larynx with $61 \%(n=46)$, the hypopharynx with $19 \%(n=14)$ and the supraglottic larynx with $16 \%(n=12)$. Regarding the recurrent tumor sites after prior surgery, the glottic larynx $(n=31,41 \%)$, the neopharynx $(\mathrm{n}=12,16 \%)$ and the hypopharynx $(\mathrm{n}=14,19 \%)$ dominated. At first diagnosis, $56 \%$ of the tumors were at UICC stage I-II $(n=44)$. At recurrence, higher UICC stages could be identified with $28 \%$ for UICC stage III $(n=21), 25 \%$ for UICC stage IVA $(n=19), 13 \%$ for UICC stage IVB $(n=10)$ and $1 \%$ for UICC stage IVC $(\mathrm{n}=1)$. Patient characteristics are shown in Table 1.

\section{Treatment characteristics}

For treatment planning, CT and MRI were performed and patients were immobilized with custom-made thermoplastic masks with shoulder fixation. Clinical target volume 1 (CTV1) including the macroscopic tumor and the potential microscopic spread and CTV2 including the CTV1 and the lymphatic drainage were outlined. Planning target volumes (PTVs) were generated with a margin of $5 \mathrm{~mm}$ around the CTVs and received at least $90 \%$ of the prescription dose. All patients received intensity modulated radiotherapy (IMRT) via tomotherapy with $(n=70,93 \%)$ or without simultaneous integrated boost (SIB, $n=5,7 \%$ ) at a median time of 7 months after the first operation (range 1-333 months). Single doses and prescription doses differed, thus we calculated the equivalent dose in $2 \mathrm{~Gy}$ per fraction with the following formula for better dose comparibility: $\mathrm{EQD} 2=\mathrm{D} \times((\mathrm{d}+\alpha / \beta) /(2+\alpha / \beta))(\mathrm{D}=$ total dose in $G y, d=$ single dose in $G y, \alpha / \beta=2$ ).

The median prescribed total dose was 54Gy (range 52.2-66 Gy) with a median single dose fraction of 1.8 Gy (range: $1.8-2.0 \mathrm{~Gy}$ ) to the bilateral cervical lymph drainage and $66 \mathrm{~Gy}$ (range 58-72 Gy) with a median single dose fraction of $2.2 \mathrm{~Gy}$ (range 1.8-2.2 Gy) to the macroscopic tumor. The median equivalent dose to a 2 Gy single dose fraction (EQD2) prescribed on the macroscopic tumor was $67 \mathrm{~Gy}$ (range $60-73 \mathrm{~Gy}$ ). In 5 cases, treatment could not be finished (7\%). Thus, these patients received smaller cumulative doses. The median PTV1 was $101 \mathrm{cc}$ (range 21-222 cc) and the median PTV2 was $740 \mathrm{cc}$ (range $51-1301 \mathrm{cc}$ ). Overall, 77\% of the patients were treated with concomitant systemic therapy $(n=58)$ of whom $64 \%$ received concomitant chemotherapy $(n=48)$ with carboplatin/5-fluoruracil in week 1 and $5(\mathrm{n}=4)$ or cisplatin weekly $(n=44)$ and $13 \%$ concomitant immunotherapy with cetuximab weekly $(n=10)$. Treatment characteristics are depicted in Table 2.

\section{Results}

\section{Survival analysis}

Five patients could not finish therapy for deterioration of their general condition (KPS $<60 \%$ ) and were lost to follow-up after treatment. Therefore, we excluded these patients from the analysis (7\%). Median follow-up for all remaining patients was 41 months (range $8-120$ months) and for surviving patients 50 months (range $8-120$ months). At last follow-up, $56 \%$ of the patients were still alive $(n=39)$ of whom $87 \%$ were free of local failure $(n=34)$. Median OS from first diagnosis up to last follow-up or death was 59 months (range 11-373 months) and from RT up to last follow-up or death 43 months (range 14-121 months). Overall, complete remission was seen in 48 patients (64\%) and partial remission in six patients (8\%). $20 \%$ of the patients developed an in-field recurrence $(n=14)$ and one patient a locoregional recurrence in cervical lymph nodes (1\%) after a median time of 12 months (range 3-19 months) after RT. All local and locoregional recurrences occurred within the first 2 years after RT. Distant metastases $(n=13)$ were diagnosed in $19 \%$ of the patients after a median time of 28 months (range 2-88 months) after the first diagnosis with pulmonary failure in 11 cases (16\%) and bone metastases in 2 cases (3\%). Corresponding 3-year and estimated 5-year LPFS, OS and DPFS were 75, 76, 85 and 75\%, 64, 82\% for all patients without significant differences for initially early stage (without an initial indication for adjuvant RT) vs. advanced stage (with an initial indication for adjuvant $\mathrm{RT}$ ) larynx/hypopharynx tumors in the LPFS $(p=0.431$; HR $=1.12 ; 95 \%-\mathrm{CI}=0.38-21.30)$, OS $(p=0.518 ; \mathrm{HR}=0.89$; $95 \%-\mathrm{CI}=1.24-12.46)$ and DPFS $(p=0.081 ; \mathrm{HR}=3.04$; $95 \%-\mathrm{CI}=1.98-8.34$ ), respectively. Patients with local or locoregional recurrence received either palliative systemic therapy $(n=5,7 \%)$, best supportive care $(n=1$, $1 \%)$, salvage larynx-preserving surgery $(n=2,3 \%)$, salvage $\mathrm{ND}(\mathrm{n}=1,1 \%)$, salvage total laryngectomy $(\mathrm{n}=5$, $7 \%)$ or re-RT $(n=1,1 \%)$. Thus, preservation of the larynx could be achieved in $90 \%(n=47 / 52)$ of the patients apart from patients who were initially treated by total laryngectomy.

\section{Prognostic factors for survival}

We analysed the impact of potential prognostic factors at time of first-line treatment with surgery alone (initial T, N, $\mathrm{G}$ stage, ECS, tumor site, Karnofsky performance status (KPS), prior laryngectomy vs. larynx-preserving surgery, prior ND yes vs. no, time period between first operation 
Table 1 Patient and tumor characteristics at first-line and second-line treatment, $n=75$

\begin{tabular}{|c|c|c|}
\hline \multirow[t]{2}{*}{ characteristic } & \multicolumn{2}{|l|}{ No. (\%) } \\
\hline & $\begin{array}{l}\text { first-line treatment } \\
\text { (surgery) }\end{array}$ & $\begin{array}{l}\text { second-line treatment } \\
\text { (RT/CRT) }\end{array}$ \\
\hline median age (years) & $59(42-83)$ & $62(46-83)$ \\
\hline \multicolumn{3}{|l|}{ gender } \\
\hline male & $64(85)$ & $64(85)$ \\
\hline female & $11(15)$ & $11(15)$ \\
\hline \multicolumn{3}{|l|}{$\begin{array}{l}\text { Karnofsky performance } \\
\text { score in \% }\end{array}$} \\
\hline 100 & $25(33)$ & $12(16)$ \\
\hline 90 & $18(24)$ & $23(31)$ \\
\hline 80 & $24(32)$ & $17(23)$ \\
\hline 70 & $8(11)$ & $17(23)$ \\
\hline 60 & none & $6(8)$ \\
\hline \multicolumn{3}{|l|}{ tumor site } \\
\hline glottic larynx & $46(61)$ & $31(41)$ \\
\hline subglottic larynx & $3(4)$ & $10(13)$ \\
\hline supraglottic larynx & $12(16)$ & $8(11)$ \\
\hline hypopharynx & $14(19)$ & $14(19)$ \\
\hline neopharynx & none & $12(16)$ \\
\hline \multicolumn{3}{|l|}{ UICC stage } \\
\hline । & $20(27)$ & $16(21)$ \\
\hline$\|$ & $22(29)$ & $8(11)$ \\
\hline III & $9(12)$ & $21(28)$ \\
\hline IVA & $22(29)$ & $19(25)$ \\
\hline IVB & $1(1)$ & $10(13)$ \\
\hline IVC & $1(1)$ & $1(1)$ \\
\hline \multicolumn{3}{|l|}{ TNM stage } \\
\hline $\mathrm{T} 1$ & $22(29)$ & $22(29)$ \\
\hline $\mathrm{T} 2$ & $25(33)$ & $12(16)$ \\
\hline T3 & $14(19)$ & $15(20)$ \\
\hline T4 & $14(19)$ & $26(35)$ \\
\hline NO & $51(68)$ & $48(64)$ \\
\hline $\mathrm{N} 1$ & $3(4)$ & $11(15)$ \\
\hline N2 & $20(27)$ & $14(19)$ \\
\hline N3 & $1(1)$ & $1(1)$ \\
\hline MO & $74(99)$ & $73(97)$ \\
\hline M1 & $1(1)$ & $2(3)$ \\
\hline \multicolumn{3}{|l|}{ G stage } \\
\hline G1 & $2(3)$ & $2(3)$ \\
\hline $\mathrm{G} 2$ & $51(68)$ & $49(65)$ \\
\hline G3 & $19(25)$ & $21(28)$ \\
\hline Gx & $3(4)$ & $3(4)$ \\
\hline
\end{tabular}

abbreviations: $R T$ radiotherapy, $C R T$ chemoradiotherapy, $T$ tumor stage, $N$ nodal stage, $M$ metastasis stage, $G$ grading, UICC Union Internationale Contre le Cancer
Table 2 Treatment characteristics at first-line and second-line treatment, $n=75$

\begin{tabular}{ll}
\hline first-line treatment (surgery) & \\
number of previous surgeries & $46(61)$ \\
1 & $17(23)$ \\
2 & $10(13)$ \\
3 & $2(3)$ \\
4 & $18(24)$ \\
total laryngetomy & $57(76)$ \\
larynx-preserving surgery & $2(3)$ \\
$\quad$ vocal cord tripping & $21(28)$ \\
endoscopic laser resection & $34(45)$ \\
partial laryngectomy & $10(13)$ \\
unilateral ND & $27(36)$ \\
bilateral ND & $11(30)$ \\
ECS & \\
second-line treatment (RT/CRT) & 67 Gy (60-72 Gy) \\
median EQD2 in Gy & $101 \mathrm{cc}(21-1949$ cc) \\
median PTV1 & $740 \mathrm{cc}(51-72 \mathrm{cc})$ \\
median PTV2 & $48(64)$ \\
concomitant chemotherapy & $10(13)$ \\
concomitant cetuximab & \\
\hline
\end{tabular}

abbreviations: $R T$ radiotherapy, CRT chemoradiotherapy, ECS extracapsular spread, $E Q D 2$ equivalent dose in $2 \mathrm{~Gy}$ single dose fractions, $N D$ neck dissection, PTV planning target volume

and first recurrence) and at time of second-line treatment with salvage RT (recurrent T, N, G stage, KPS, number of prior operations, EQD2 > 70 Gy vs. $\leq 70$ Gy, PTV1 $\geq 101 \mathrm{cc}$ vs. $<101 \mathrm{cc}$, cisplatin weekly chemotherapy vs. others, local recurrences yes vs. no after RT and metastases yes vs. no) on OS, LPFS and DPFS. Several potential prognostic factors were identified using the log-rank test for univariate analyses. Independent prognostic factors were assessed by the cox regression model for multivariate analysis. The results of univariate and multivariate analysis are shown in Table 3.

Regarding LPFS, we could identify the use of concomitant chemotherapy with cisplatin weekly $(p=0.006)$ and an EQD2 > 70Gy prescribed on the macroscopic tumor as positive prognostic factors $(p=0.032)$. Patients who received concomitant systemic therapy were included into analysis only. The use of concomitant chemotherapy with cisplatin weekly resulted in a 5-year LPFS of $86 \%$ vs. $44 \%$ compared with patients who received concomitant chemotherapy with carboplatin/5-FU in week 1 and 5 or cetuximab weekly (Fig. 1). With regard to the applied EQD2 on the macroscopic recurrent tumor, patients who received an EQD2 $>70$ Gy had a 5-year LPFS of $90 \%$ vs. $68 \%$ compared with patients who received an EQD2 $\leq 70$ Gy (Fig. 2). 
Table 3 Results $(n=70)$

\begin{tabular}{|c|c|c|c|c|c|}
\hline \multirow[t]{2}{*}{ characteristics } & \multirow{2}{*}{$\begin{array}{l}\text { 5-year } \\
\text { survival }\end{array}$} & \multicolumn{2}{|l|}{ univariate analysis } & \multicolumn{2}{|c|}{ multivariate analysis } \\
\hline & & HR (95\%-KI) & $p$ value & HR $(95 \%-K I)$ & $p$ value \\
\hline \multicolumn{6}{|l|}{ overall survival } \\
\hline \multicolumn{6}{|l|}{ at first-line treatment (surgery) } \\
\hline iT stage (T3/4 vs. T1/2) & $45 \%$ vs. $72 \%$ & $1.46(1.01-2.11)$ & 0.041 & & \\
\hline iN stage (N+ vs. N0) & $25 \%$ vs. $78 \%$ & $5.78(2.66-12.59)$ & 0.000 & $2.50(0.96-6.49)$ & 0.060 \\
\hline \multicolumn{6}{|l|}{ at second-line treatment (RT/CRT) } \\
\hline \multicolumn{6}{|l|}{ recurrent tumor site (others vs. } \\
\hline glottis) & $42 \%$ vs. $89 \%$ & $4.70(1.79-12.33)$ & 0.001 & $4.77(1.00-22.70)$ & 0.050 \\
\hline rKPS ( $\geq 90 \%$ vs. $<90 \%)$ & $68 \%$ vs. $36 \%$ & $0.55(0.35-0.84)$ & 0.050 & & \\
\hline chemotherapy (others vs. cisplatin weekly) & $35 \%$ vs. $64 \%$ & $2.37(1.04-5.45)$ & 0.035 & & \\
\hline \multicolumn{6}{|l|}{ local recurrence after RT } \\
\hline (yes vs. no) & $25 \%$ vs. $74 \%$ & $3.10(1.44-6.67)$ & 0.002 & $2.63(1.04-6.69)$ & 0.041 \\
\hline metastases after RT (yes vs. no) & $3 \%$ vs. $70 \%$ & $3.44(1.54-7.71)$ & 0.001 & & \\
\hline \multicolumn{6}{|l|}{ local progression-free survival } \\
\hline \multicolumn{6}{|l|}{ at first-line treatment (surgery) } \\
\hline iN stage (N+ vs. N0) & $50 \%$ vs. $86 \%$ & $4.52(1.60-12.72)$ & 0.002 & $3.62(0.92-14.19)$ & 0.065 \\
\hline iG stage (G3 vs. G1/2) & $59 \%$ vs. $82 \%$ & $2.77(1.00-7.66)$ & 0.038 & & \\
\hline \multicolumn{6}{|l|}{ at second-line treatment (RT/CRT) } \\
\hline rG stage (G3 vs. G1/2) & $59 \%$ vs. $82 \%$ & $2.66(1.04-7.80)$ & 0.036 & & \\
\hline EQD2 (> 70 Gy vs. =70 Gy) & $90 \%$ vs. $68 \%$ & $0.25(0.06-1.10)$ & 0.045 & $0.10(0.01-0.82)$ & 0.032 \\
\hline chemotherapy (others vs. cisplatin weekly) & $46 \%$ vs. $86 \%$ & $5.78(1.75-19.13)$ & 0.001 & $3.62(0.92-14.19)$ & 0.006 \\
\hline \multicolumn{6}{|l|}{ distant progression-free survival } \\
\hline \multicolumn{6}{|l|}{ at first-line treatment (surgery) } \\
\hline iN stage (N+ vs. N0) & $40 \%$ vs. $89 \%$ & $6.19(1.85-20.76)$ & 0.001 & $2.56(1.03-6.34)$ & 0.042 \\
\hline iG stage (G3 vs. G1/2) & $65 \%$ vs. $85 \%$ & $3.06(1.03-9.13)$ & 0.035 & $3.45(0.98-12.23)$ & 0.055 \\
\hline \multicolumn{6}{|l|}{ at second-line treatment (RT/CRT) } \\
\hline rT stage (T3/4 vs. T1/2) & $70 \%$ vs. $90 \%$ & $3.30(0.91-11.99)$ & 0.055 & $6.02(1.29-30.00)$ & 0.028 \\
\hline rG stage (G3 vs. G1/2) & $65 \%$ vs. $85 \%$ & $3.12(1.00-9.25)$ & 0.037 & $3.45(0.98-12.23)$ & 0.054 \\
\hline \multicolumn{6}{|l|}{ recurrent tumor site (others vs. } \\
\hline glottis) & $68 \%$ vs. $100 \%$ & $6.02(0.68-10.24)$ & 0.014 & & \\
\hline \multicolumn{6}{|l|}{ PTV1 volume (=median vs. } \\
\hline <median of $101 \mathrm{cc}$ ) & $65 \%$ vs. $87 \%$ & $3.85(1.04-14.22)$ & 0.030 & $5.39(1.65-12.53)$ & 0.038 \\
\hline chemotherapy (others vs. cisplatin weekly) & $57 \%$ vs. $82 \%$ & $3.27(1.03-10.41)$ & 0.034 & & \\
\hline
\end{tabular}

abbreviations: EQD2 equivalent dose to $2 \mathrm{~Gy}$ single fraction, $H R$ hazard ratio, iT stage initial tumor stage, iN stage initial nodal stage, KPS Karnofsky performance score, $R T$ radiotherapy, $C R T$ chemoradiotherapy, $G$ stage grading stage, $r T$ stage recurrent tumor stage, $P T V$ planning target volume

Patients with local or locoregional recurrence after salvage RT had a significant worse OS with a 5-year OS of $25 \%$ vs. $74 \%$ estimated from Kaplan-Meier analysis compared with patients who were free from recurrence at last follow-up $(p=0.041)$, respectively. Furthermore, recurrent tumor site showed an estimated impact on patients' OS. Thus, patients with glottic recurrence had a survival benefit with a 5-year OS rate of $89 \%$ compared with patients who had recurrences in the area of the supraglottic or subglottic larynx, hypopharynx or neopharynx with a 5 -year OS rate of $25 \%(p=0.05)$. Additionally, initial $\mathrm{N}$ stage seemed to have a further impact on OS with a survival benefit for patients without initial lymph node metastases, but in the multivariate analysis, the significance level could not be achieved $(p=0.06)$.

In terms of DPFS, recurrent T stage showed the most significant impact on DPFS with a 5-year DPFS of $90 \%$ for $\mathrm{rT} 1 / 2$ tumors and $70 \%$ for $\mathrm{rT} 3 / 4$ tumors $(p=0.028)$. Further, PTV1 ( $\geq$ median of 101 cc vs. < median of 101 $c c)$ had a worse impact on DPFS with increasing volume $(p=0.038)$. At least, initial $\mathrm{N}$ stage could be diagnosed as further prognostic factor for DPFS with a significant 


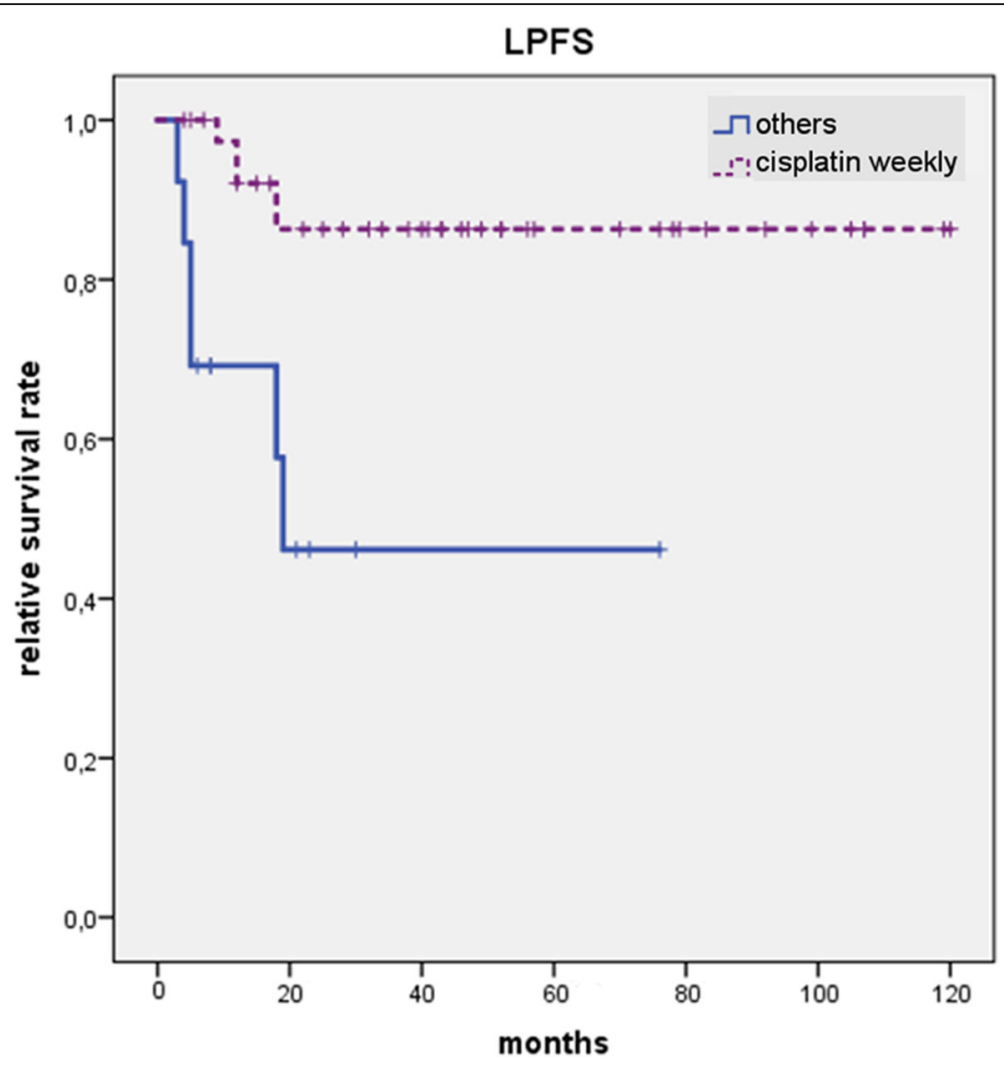

Fig. 1 LPFS depends significantly on the use of concomitant systemic therapy with survival benefit for patients receiving cisplatin weekly chemotherapy vs. Others (carboplatin/5-fluoruracil and cetuximab) ( $p=0.006$ ). 5-year LPFS amounts $86 \%$ vs. $43 \%$ for patients who received concomitant cisplatin weekly vs. patients who did not

lower occurrence of metastases for iN0 stage compared with iN+ stage $(p=0.042)$. Increasing $\mathrm{N}+$ stage (N1 vs. $\mathrm{N} 2$ vs. N3) had no impact on DPFS $(p=0.140)$.

\section{Toxicity}

Overall, $20 \%$ of the patients reported acute grade 3 $(n=14)$ and $19 \%$ of the patients chronic grade 3 and grade 4 toxicity $(n=13)$. During and six weeks after therapy, no acute grade 4 toxicity could be identified. An overview of acute and late side effects is shown in Table 4 . Acute grade 3 toxicity consisted of mucositis $(n=2,3 \%)$, dysphagia $(6 \%, n=4)$, odynophagia $(n=5$, $7 \%)$, dermatitis $(\mathrm{n}=4,6 \%)$, xerostomia $(\mathrm{n}=1,1 \%)$, hoarseness $(n=3,4 \%)$ and lymphedema $(n=1,1 \%)$. Three months after therapy, the majority of the acute grade 3 side effects disappeared. Nevertheless, 3 patients received tracheostomy for acute dyspnea due to grade 4 lymphedema of the larynx (4\%) and in one patient a laryngoesophageal fistula could be diagnosed 6 months after therapy (1\%). 3 patients claimed about chronic severe dysphagia with high-grade stenosis of the laryngoesophageal junction with the need of regular bougienage up to the last follow-up (4\%). Further, one patient developed a laryngocutaneous fistula 12 months after RT (1\%) and one patient developed a wound healing disorder in radiation field 24 months after therapy (1\%).

Under RT, $43 \%$ of the patients needed supportive nutrition for nutritional difficulties due to acute side effects $(n=30)$. Acute gastric tube dependence counted $34 \%(n=24) .3$ to 6 months after therapy, only $13 \%$ of the patients needed farther a gastric tube for nutrition $(n=9)$. Only one patient was dependent on a gastric tube for more than 2 years $(1 \%)$.

\section{Discussion}

\section{Findings}

The majority of the patients in the current analysis were treated with dose-escalated RT (93\%) and concomitant cisplatin weekly chemotherapy (60\%) for recurrent laryngeal or hypopharyngeal SCC after firstline treatment with surgery alone. Two thirds of the patients had tumors in advanced stages (UICC III and IV) before treatment. Nevertheless, we identified an excellent 3-year LPFS, OS and DPFS of 75, 76 and $85 \%$ and an estimated 5-year LPFS, OS and DPFS of 75,64 and $82 \%$, respectively. The 5-year local control rate was $79 \%$ for this unfavourable patient population. All recurrences occurred in-field and within the first 


\section{LPFS}

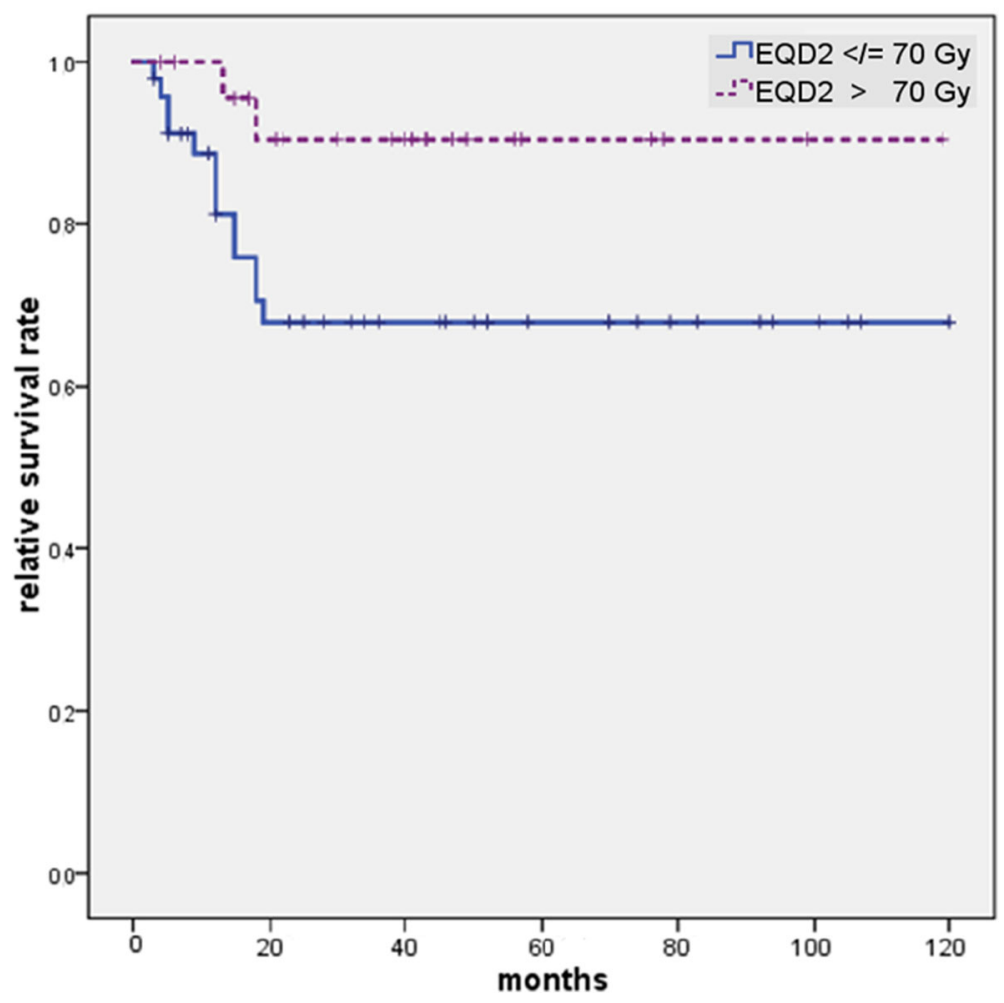

Fig. 2 LPFS depends significantly on the applied RT dose with survival benefit for patients receiving an EQD2 > 70 Gy ( $p=0.032)$. Patients who received an EQD2 > 70 Gy show a 5-year LPFS of 90\% vs. 68\% compared with patients who received an EQD2 $\leq 70$ Gy

two years after treatment. Larynx-preservation could be observed in $90 \%$ of the patients who received organ-preserving surgery as initial treatment. Local control was best achieved in patients receiving an EQD2 $>70 \mathrm{~Gy}$ on the macroscopic tumor and concomitant chemotherapy with cisplatin weekly. RT dose and the use of cisplatin chemotherapy did not correlate with patients' KPS $(p=0.139)$. OS depended negatively on the occurrence of local recurrences after salvage RT and on the recurrent tumor site before RT with survival benefit for recurrent tumors involving the glottis. DPFS differed significantly regarding recurrent tumor size and the initial nodal stage. Overall, compliance was well (93\%) and RT was tolerated with moderate toxicity.

\section{Survival results}

Nowadays, CRT is seen as an equivalent therapy option to surgery regarding tumor control in laryngeal and hypoharyngeal tumors $[11,12]$. Thus, Mendenhall et al. reported $2001 \mathrm{RT}$ alone for T1/2 N0 larynx tumors as an alternative curative therapy option to surgery with a comparable 5-year LPFS of 72 to $94 \%$ depending on T stage, a 5 -year OS of $79 \%$ and a 5 -year DPFS of $98 \%$ [13]. Nevertheless, surgery in form of organ-preserving endoscopic resection, laser surgery or open-neck partial laryngectomy is still considered as the gold standard in the treatment of early stage tumors with local control rates of 60 to $95 \%$, declining with increasing $\mathrm{T}$ stage [12]. While local relapses are relatively rare after primary treatment of early stage tumors, local control in advanced hypopharyngeal and laryngeal tumors remains a challenge. As organ-preserving treatment strategies are increasingly used as first-line treatment, the use of organ-preserving RT in combination with chemotherapy for advanced stages gained in importance within the last decades $[5,13,14]$. However, 40 to $60 \%$ of patients with advanced tumors relapse after primary CRT $[5,15]$. Salvage treatment options for these patients are limited, as re-irradiation is mostly limited by the tumor site and the necessary prescription dose to the recurrent tumor. In these cases, salvage surgery is mostly required. The effectiveness of salvage surgery after failure of primary CRT (2-year OS between 27 and 71\%) is reported by several studies [16-18]. Taguchi et al. reported a 5-year OS and disease-specific survival of 61 and $66 \%$ for salvage surgery after primary CRT vs. 10 and $10 \%$ for patients who failed primary CRT but did not undergo salvage surgery [18]. While poor prognosis with a 5 -year OS of $16 \%$ is described for recurrent hypopharyngeal tumors after salvage 
Table 4 Overview of acute and chronic toxicity $(n=70)$

\begin{tabular}{|c|c|c|c|c|c|}
\hline \multirow[t]{3}{*}{ characteristic } & \multirow{3}{*}{$\begin{array}{l}\text { acute toxicity }(n=70) \\
\text { No. }(\%) \\
\text { under RT and } 6 \text { weeks post RT }\end{array}$} & \multicolumn{4}{|c|}{ chronic toxicity $(n=63)$} \\
\hline & & \multicolumn{4}{|l|}{ No. (\%) } \\
\hline & & 3-6 months post RT & 12 months post RT & 24 months post RT & at last follow-up \\
\hline \multicolumn{6}{|l|}{ toxicity } \\
\hline grade 1 & $10(14)$ & $19(27)$ & $22(31)$ & $23(33)$ & $17(24)$ \\
\hline grade 2 & $39(56)$ & $21(30)$ & $10(14)$ & $6(9)$ & $5(7)$ \\
\hline grade 3 & $14(20)$ & $4(6)$ & $3(4)$ & $3(4)$ & $3(4)$ \\
\hline grade 4 & 0 & $4(6)$ & $1(1)$ & $1(1)$ & \\
\hline \multicolumn{6}{|l|}{ dysphagia } \\
\hline grade 1 & $6(9)$ & $7(10)$ & $6(9)$ & $6(9)$ & $5(7)$ \\
\hline grade 2 & $28(40)$ & $4(6)$ & $5(7)$ & $1(1)$ & 0 \\
\hline grade 3 & $4(6)$ & $3(4)$ & $3(4)$ & $3(4)$ & $3(4)$ \\
\hline \multicolumn{6}{|l|}{ odynophagia } \\
\hline grade 1 & $8(11)$ & $1(1)$ & 0 & 0 & 0 \\
\hline grade 2 & $14(20)$ & 0 & 0 & 0 & 0 \\
\hline grade 3 & $5(7)$ & 0 & 0 & 0 & 0 \\
\hline \multicolumn{6}{|l|}{ mucositits } \\
\hline grade 1 & $12(17)$ & $1(1)$ & 0 & 0 & 0 \\
\hline grade 2 & $36(51)$ & 0 & 0 & 0 & 0 \\
\hline grade 3 & $2(3)$ & 0 & 0 & 0 & 0 \\
\hline \multicolumn{6}{|l|}{ dermatitis } \\
\hline grade 1 & $19(27)$ & $2(3)$ & 0 & 0 & 0 \\
\hline grade 2 & $18(26)$ & $1(1)$ & 0 & 0 & 0 \\
\hline grade 3 & $4(6)$ & 0 & 0 & 0 & 0 \\
\hline \multicolumn{6}{|l|}{ xerostomia } \\
\hline grade 1 & $32(46)$ & $30(43)$ & $17(24)$ & $13(19)$ & $10(14)$ \\
\hline grade 2 & 1217() & $4(6)$ & $2(3)$ & $2(3)$ & $2(3)$ \\
\hline grade 3 & $1(1)$ & 0 & 0 & 0 & 0 \\
\hline \multicolumn{6}{|l|}{ hoarseness } \\
\hline grade 1 & $16(23)$ & $15(21)$ & $13(19)$ & $12(17)$ & $10(14)$ \\
\hline grade 2 & $13(19)$ & $7(10)$ & $3(4)$ & $1(1)$ & $2(3)$ \\
\hline grade 3 & $3(4)$ & $1(1)$ & $1(1)$ & $1(1)$ & 0 \\
\hline \multicolumn{6}{|l|}{ fatigue } \\
\hline grade 1 & $6(9)$ & $3(4)$ & $2(3)$ & $1(1)$ & $1(1)$ \\
\hline grade 2 & $6(9)$ & $2(3)$ & $1(1)$ & 0 & 0 \\
\hline \multicolumn{6}{|l|}{ dysgeusia } \\
\hline grade 1 & $11(16)$ & $14(20)$ & $11(16)$ & $8(11)$ & $7(10)$ \\
\hline grade 2 & $20(29)$ & $4(6)$ & 0 & 0 & 0 \\
\hline \multicolumn{6}{|l|}{ dry cough } \\
\hline grade 1 & $7(10)$ & $5(7)$ & $2(3)$ & $2(3)$ & 0 \\
\hline grade 2 & $1(1)$ & 0 & 0 & 0 & 0 \\
\hline \multicolumn{6}{|l|}{ lymphedema } \\
\hline grade 1 & $6(9)$ & $12(17)$ & $2(3)$ & $1(1)$ & $1(1)$ \\
\hline grade 2 & $8(11)$ & $2(3)$ & $1(1)$ & $1(1)$ & $4(6)$ \\
\hline grade 3 & $1(1)$ & $1(1)$ & $1(1)$ & $1(1)$ & $1(1)$ \\
\hline
\end{tabular}


Table 4 Overview of acute and chronic toxicity $(n=70)$ (Continued)

\begin{tabular}{|c|c|c|c|c|c|}
\hline \multirow[t]{3}{*}{ characteristic } & \multirow{3}{*}{$\begin{array}{l}\text { acute toxicity }(n=70) \\
\text { No. }(\%) \\
\text { under RT and } 6 \text { weeks post RT }\end{array}$} & \multicolumn{4}{|l|}{ chronic toxicity $(n=63)$} \\
\hline & & \multicolumn{4}{|l|}{ No. (\%) } \\
\hline & & 3-6 months post RT & 12 months post RT & 24 months post RT & at last follow-up \\
\hline grade $4^{a}$ & 0 & $3(4)$ & 0 & 0 & 0 \\
\hline \multicolumn{6}{|l|}{ fistula } \\
\hline laryngoesophageal & 0 & $1(1)$ & 0 & 0 & 0 \\
\hline laryngocutaneous & 0 & 0 & $1(1)$ & 0 & 0 \\
\hline wound healing disorder & 0 & 0 & 0 & $1(1)$ & 0 \\
\hline gastric tube dependence & $24(34)$ & $9(13)$ & $5(7)$ & $1(1)$ & $1(1)$ \\
\hline
\end{tabular}

abbreviations: $R T$ radiotherapy

${ }^{a}$ with tracheotomy for acute dyspnea

surgery, the same treatment method offers 5-year OS rates ranging from 57 to $70 \%$ for recurrent laryngeal tumors [19-21]. Recurrent hypopharyngeal tumors are mostly considered inoperable and should, therefore, be treated with alternative salvage methods [22]. Salvage CRT is generally reserved for recurrent tumors after primary total laryngectomy, for patients with inoperable recurrent tumors or in cases, where the patient rejects total laryngectomy as the only remaining treatment option in order to further preserve the organ function. Patients who receive salvage CRT mostly appear with initially early stage tumors and represent a non-comparable patient collective to patients who receive salvage surgery after failure of primary CRT. Nevertheless, studies describing a homogeneous patient population after salvage CRT including recurrent hypopharyngeal and laryngeal tumors only are lacking. Lee et al. reported a 2-year OS and progressionfree survival of 74 and $68 \%$ for patients with recurrent hypopharyngeal and laryngeal tumors who underwent different salvage treatment methods, i.e. salvage surgery with or without RT, RT alone, chemotherapy alone, after different initial treatments, i.e. CRT for advanced tumors or primary surgery for early stage tumors [23]. Li et al. analysed patients who were initially treated with surgery, RT or CRT for recurrent laryngeal tumors. The patients received salvage treatment with surgery for operable recurrent tumors in $54 \%$ and radiation in $16 \%$ of the cases [24]. Salvage surgery resulted in a 5-year OS rate of $73 \%$ vs. $32 \%$ for other salvage treatment methods like RT, while the high OS rate for salvage surgery and the decreased OS of salvage RT were discussed via patient selection bias (operable tumors, initial tumor stage). This could be a valuable reason for the excellent survival results in the current analysis as well, as the majority of our patients had initially early stage tumors (56\% UICC I/II). Nevertheless, survival analysis showed no significant difference in the LPFS, OS and DPFS for initially early stage and initially advanced tumors.

\section{Prognostic factors}

Several meta-analyses and randomized studies have proven the beneficial role of concomitant chemotherapy in combination with RT, especially regarding cisplatin chemotherapy, showing superior local control and OS rates in laryngeal/hypopharyngeal tumors as well as in other $\mathrm{HNC}$ either in the primary or postoperative setting [5, 15, 25-27]. Besides an EQD2 > 70 Gy achieved by using fractionation doses $>2 \mathrm{~Gy}$, we could identify a significant impact of cisplatin chemotherapy on LPFS only [28, 29]. Nevertheless, Pignon et al. could show in the $\mathrm{MACH}-\mathrm{NC}$ meta-analysis that chemotherapy with carboplatin and 5-fluoruracil is considered to be equivalent to cisplatin chemotherapy. The results of the current study could possibly be explained by patient selection bias between both groups [30]. In the current literature, further factors influencing LPFS, i.e. T stage, $\mathrm{N}$ stage, G stage, sex, age, vocal cord invasion, overall treatment time and RT field size are discussed in the first-line treatment $[13,31-34]$. Glottic tumors seem to have a survival benefit compared with other tumor sites, thus in several studies superior OS rates are described [1720]. The occurrence of local recurrence after treatment, tumor size and $\mathrm{N}$ stage are accepted as further prognostic factors [31-35]. For second-line treatment, initial tumor in the hypopharynx vs. the larynx, recurrent tumor in the hypopharynx vs. the larynx, advanced primary tumor, advanced recurrent tumor, advanced primary $\mathrm{N}$ stage and advanced initial and recurrent $\mathrm{G}$ stage were most frequently associated with decreased progression-free survival resulting in a poor prognosis $[23,24,36]$. In multivariate analysis, we could not identify an impact of tumor size and $\mathrm{N}$ stage on OS, possibly due to the low patient number but on DPFS. Thus, tumors with initial $\mathrm{N}+$ stage and increased recurrent tumor size (PTV1, rT stage) influenced distant control negatively [34]. Additionally, tumor differentiation ( $\mathrm{G}$ stage) can be considered as further prognostic factor regarding DPFS [31]. 


\section{Toxicity}

Superior dose conformity and decreased toxicity due to improved preservation of organs at risk compared with 3D-RT is described for IMRT [37-40]. Nevertheless, toxicity after IMRT remains high [41-45]. Especially in the hypopharynx and larynx region, significant higher rates of late side effects occur due to the proximity of several organs at risk compared with other regions of the head and neck [45]. For patients treated with concurrent CRT, Forastiere et al. could show in the RTOG trial 91-11 a high rate of severe late grade 3 and 4 toxicity, especially regarding mucositis (43\%) [44]. In a RTOG analysis of three RTOG trials (RTOG 91-11, RTOG 97-03, RTOG 99-14), Machtay et al. identified 43\% late side effects after CRT for locally advanced squamous cell carcinoma of the head and neck, and described grade 3 and 4 pharyngeal and laryngeal dysfunction in $39 \%$, gastric tube dependence longer than 2 years in $13 \%$ and treatment-related death within 3 years in $10 \%$ of the patients. Swallowing limitations, aspiration, laryngoesophageal stricture and dysphagia dominated regarding laryngoesophageal dysfunction [45]. Caudell et al. reported a 3-year laryngoesophageal dysfunction-free survival (LEDFS) of 32\% for patients who were treated with CRT for advanced SCC of the larynx and hypopharynx [42]. For salvage treatment methods as well, high toxicity rates are reported. Several authors described complication rates between 44 and 59\% for salvage surgery after first-line CRT $[16,17,46]$. A systematic review and meta-analysis of the complications of salvage total laryngectomy including 3293 patients by Hasan et al. showed a complication rate of $68 \%$ with $29 \%$ pharyngocutaneous fistula [47].In the current analysis, in contrast, only $19 \%$ of the patients claimed about severe chronic toxicity. Especially laryngoesophageal dysfunction consisting of severe dysphagia (4\%), fistula (3\%), dyspnea (4\%) or wound healing disorder (1\%) were observed. Only one patient showed feeding tube dependence over 2 years after RT (1\%). We could not identify any treatment-related deaths within the follow-up time. Despite first-line surgery and second-line dose-escalated RT, we identified moderate toxicity rates making salvage CRT after failed surgery a safe therapy alternative.

\section{Conclusion}

Salvage radiotherapy is an effective curative therapy option for recurrent hypopharyngeal and laryngeal SCC after prior surgery with excellent local control rates and moderate toxicity comparable to prior results concerning primary radiotherapy. We recommend dose-escalated IMRT with an EQD2 > 70 Gy as well as the use of concomitant cisplatin weekly chemotherapy for superior LPFS. Nevertheless, patient selection for curative salvage treatment remains challenging.

\section{Acknowledgements}

We thank our Head and Neck Cancer Research Group members for their great effort.

\section{Funding}

The study is financed by the Department of Radiation Oncology of the University Hospital Heidelberg. There is no external funding source.

\section{Availability of data and materials}

The data used in this analysis is from publications available in the public domain.

\section{Authors' contributions}

SaA and SeA developed and planned the retrospective analysis. All authors read and approved the final manuscript.

\section{Ethics approval and consent to participate}

The current study was performed according the principles of the Declaration of Helsinki. The final protocol was approved by the ethics committee of the University of Heidelberg, Heidelberg, Germany (S-421/2015).

Consent for publication

Not applicable.

\section{Competing interests}

The authors declare that they have no competing interests.

\section{Publisher's Note}

Springer Nature remains neutral with regard to jurisdictional claims in published maps and institutional affiliations.

\section{Author details}

${ }^{1}$ Department of Radiation Oncology, University Hospital Heidelberg, Im Neuenheimer Feld 400, 69120 Heidelberg, Germany. ${ }^{2}$ Heidelberg Institute for Radiation Oncology (HIRO), National Center for Radiation Research in Oncology (NCRO), Im Neuenheimer Feld 400, 69120 Heidelberg, Germany. ${ }^{3}$ Heidelberg lon-Beam Therapy Center (HIT), Im Neuenheimer Feld 450, 69120 Heidelberg, Germany. ${ }^{4}$ Department of Otorhinolaryngology, Head and Neck Surgery, University Hospital Heidelberg, Im Neuenheimer Feld 400, 69120 Heidelberg, Germany.

Received: 2 November 2018 Accepted: 8 February 2019

Published online: 19 February 2019

\section{References}

1. Duke RL, Campbell BH, Indresano AT, Eaton DJ, Marbella AM, Myers KB, Layde PM. Dental status and quality of life in long-term head and neck cancer survivors. Laryngoscope. 2005;115(4):678-83.

2. Jensen $A B$, Hansen $O$, Jorgensen $K$, Bastholt $L$. Influence of late side-effects upon daily life after radiotherapy for laryngeal and pharyngeal cancer. Acta Oncol. 1994;33(5):487-91.

3. Langendijk JA, Doornaert P, Verdonck-de Leeuw IM, Leemans CR, Aaronson NK, Slotman BJ. Impact of late treatment-related toxicity on quality of life among patients with head and neck cancer treated with radiotherapy. J Clin Oncol. 2008;26(22):3770-6.

4. Department of Veterans Affairs Laryngeal Cancer Study G, Wolf GT, Fisher SG, Hong WK, Hillman R, Spaulding M, Laramore GE, Endicott JW, McClatchey K, Henderson WG. Induction chemotherapy plus radiation compared with surgery plus radiation in patients with advanced laryngeal cancer. N Engl J Med. 1991;324(24):1685-90.

5. Forastiere AA, Goepfert H, Maor M, Pajak TF, Weber R, Morrison W, Glisson B, Trotti A, Ridge JA, Chao C, et al. Concurrent chemotherapy and radiotherapy for organ preservation in advanced laryngeal cancer. $\mathrm{N}$ Engl J Med. 2003;349(22):2091-8.

6. Liu J, Zhang Y, Li Z, LiU S, Li H, Xu Z. Benefit of salvage total pharyngolaryngoesophagectomy for recurrent locally advanced head and neck cancer after radiotherapy. Radiat Oncol. 2017;12(1):164.

7. Pujo K, Philouze P, Scalabre A, Ceruse P, Poupart M, Buiret G. Salvage surgery for recurrence of laryngeal and hypopharyngeal squamous cell carcinoma: a retrospective study from 2005 to 2013. Eur Ann Otorhinolaryngol Head Neck Dis. 2017;135(2):111-117. 
8. Therasse P, Arbuck SG, Eisenhauer EA, Wanders J, Kaplan RS, Rubinstein L, Verweij J, Van Glabbeke M, van Oosterom AT, Christian MC, et al. New guidelines to evaluate the response to treatment in solid tumors. European Organization for Research and Treatment of Cancer, National Cancer Institute of the United States, National Cancer Institute of Canada. J Natl Cancer Inst. 2000;92(3):205-16.

9. Eisenhauer EA, Therasse P, Bogaerts J, Schwartz LH, Sargent D, Ford R, Dancey J, Arbuck S, Gwyther S, Mooney M, et al. New response evaluation criteria in solid tumours: revised RECIST guideline (version 1.1). Eur J Cancer. 2009;45(2):228-47.

10. Lydiatt WM, Ridge JA, Patel SG, et al. Oropharynx (p16-) and Hypopharynx, AJCC Cancer Staging Manual, 8th, Amin MB (Ed.). New York: Springer; 2017. p. 123. 149

11. Ganly I, Patel SG, Matsuo J, Singh B, Kraus DH, Boyle J, Wong RJ, Lee N, Pfister DG, Shaha AR, et al. Predictors of outcome for advanced-stage supraglottic laryngeal cancer. Head Neck. 2009;31(11):1489-95.

12. Mendenhall WM, Werning JW, Hinerman RW, Amdur RJ, Villaret DB. Management of T1-T2 glottic carcinomas. Cancer. 2004;100(9):1786-92.

13. Mendenhall WM, Amdur RJ, Morris CG, Hinerman RW. T1-T2NO squamous cell carcinoma of the glottic larynx treated with radiation therapy. J Clin Oncol. 2001;19(20):4029-36.

14. American Society of Clinical O, Pfister DG, Laurie SA, Weinstein GS, Mendenhall WM, Adelstein DJ, Ang KK, Clayman GL, Fisher SG, Forastiere AA, et al. American Society of Clinical Oncology clinical practice guideline for the use of larynx-preservation strategies in the treatment of laryngeal cancer. J Clin Oncol. 2006:24(22):3693-704.

15. Pignon JP, Bourhis J, Domenge C, Designe L. Chemotherapy added to locoregional treatment for head and neck squamous-cell carcinoma: three meta-analyses of updated individual data. MACH-NC Collaborative Group. Meta-Analysis of Chemotherapy on Head and Neck Cancer. Lancet. 2000; 355(9208):949-55.

16. Weber RS, Berkey BA, Forastiere A, Cooper J, Maor M, Goepfert H, Morrison W, Glisson B, Trotti A, Ridge JA, et al. Outcome of salvage total laryngectomy following organ preservation therapy: the radiation therapy oncology group trial 91-11. Arch Otolaryngol Head Neck Surg. 2003:129(1):44-9.

17. Suzuki K, Hayashi R, Ebihara M, Miyazaki M, Shinozaki T, Daiko H, Sakuraba M, Zenda S, Tahara M, Fujii S. The effectiveness of chemoradiation therapy and salvage surgery for hypopharyngeal squamous cell carcinoma. Jpn J Clin Oncol. 2013:43(12):1210-7.

18. Taguchi T, Nishimura G, Takahashi M, Shiono O, Komatsu M, Sano D, Yabuki Kl, Arai Y, Yamashita Y, Yamamoto K, et al. Treatment results and prognostic factors for advanced squamous cell carcinoma of the head and neck treated with salvage surgery after concurrent chemoradiotherapy. Int J Clin Oncol. 2016;21(5):869-74.

19. Hamoir M, Holvoet $E$, Ambroise J, Lengele B, Schmitz S. Salvage surgery in recurrent head and neck squamous cell carcinoma: oncologic outcome and predictors of disease free survival. Oral Oncol. 2017;67:1-9.

20. Sandulache VC, Vandelaar LJ, Skinner HD, Cata J, Hutcheson K, Fuller CD, Phan J, Siddiqui Z, Lai SY, Weber RS, et al. Salvage total laryngectomy after external-beam radiotherapy: a 20-year experience. Head Neck. 2016; 38(Suppl 1):E1962-8.

21. Ganly I, Patel SG, Matsuo J, Singh B, Kraus DH, Boyle JO, Wong RJ, Shaha AR Lee $N$, Shah JP. Results of surgical salvage after failure of definitive radiation therapy for early-stage squamous cell carcinoma of the glottic larynx. Arch Otolaryngol Head Neck Surg. 2006;132(1):59-66.

22. Taki S, Homma A, Oridate N, Suzuki S, Suzuki F, Sakashita T, Fukuda S. Salvage surgery for local recurrence after chemoradiotherapy or radiotherapy in hypopharyngeal cancer patients. Eur Arch Otorhinolaryngol. 2010;267(11):1765-9.

23. Lee JR, Almuhaimid TM, Roh JL, Oh JS, Kim SJ, Kim JS, Choi SH, Nam SY, Kim SY. Prognostic value of (18) F-FDG PET/CT parameters in patients who undergo salvage treatments for recurrent squamous cell carcinoma of the larynx and hypopharynx. J Surg Oncol. 2018;118(4):644-50.

24. Li P, Hu W, Zhu Y, Liu J. Treatment and predictive factors in patients with recurrent laryngeal carcinoma: a retrospective study. Oncol Lett. 2015;10(5): 3145-52.

25. Fu KK, Pajak TF, Trotti A, Jones CU, Spencer SA, Phillips TL, Garden AS, Ridge JA, Cooper JS, Ang KK. A radiation therapy oncology group (RTOG) phase III randomized study to compare hyperfractionation and two variants of accelerated fractionation to standard fractionation radiotherapy for head and neck squamous cell carcinomas: first report of RTOG 9003. Int J Radiat Oncol Biol Phys. 2000;48(1):7-16.
26. Horiot JC, Bontemps $P$, van den Bogaert W, Le Fur R, van den Weijngaert $D$, Bolla M, Bernier J, Lusinchi A, Stuschke M, Lopez-Torrecilla J, et al. Accelerated fractionation (AF) compared to conventional fractionation (CF) improves loco-regional control in the radiotherapy of advanced head and neck cancers: results of the EORTC 22851 randomized trial. Radiother Oncol. 1997:44(2):111-21.

27. Pignon JP, le Maitre A, Bourhis J, Group M-NC. Meta-Analyses of Chemotherapy in Head and Neck Cancer (MACH-NC): an update. Int J Radiat Oncol Biol Phys. 2007;69(2 Suppl):S112-4.

28. Schwaibold F, Scariato A, Nunno M, Wallner PE, Lustig RA, Rouby E, Gorshein D, Wenger J. The effect of fraction size on control of early glottic cancer. Int J Radiat Oncol Biol Phys. 1988;14(3):451-4.

29. Kim RY, Marks ME, Salter MM. Early-stage glottic cancer: importance of dose fractionation in radiation therapy. Radiology. 1992;182(1):273-5.

30. Pignon JP, le Maitre A, Maillard E, Bourhis J, Group M-NC. Metaanalysis of chemotherapy in head and neck cancer (MACH-NC): an update on 93 randomised trials and 17,346 patients. Radiother Oncol. 2009;92(1):4-14.

31. Overgaard J, Hansen HS, Jorgensen K, Hjelm Hansen M. Primary radiotherapy of larynx and pharynx carcinoma--an analysis of some factors influencing local control and survival. Int J Radiat Oncol Biol Phys. 1986; 12(4):515-21.

32. Terhaard CH, Snippe K, Ravasz LA, van der Tweel I, Hordijk GJ. Radiotherapy in T1 laryngeal cancer: prognostic factors for locoregional control and survival, uni- and multivariate analysis. Int J Radiat Oncol Biol Phys. 1991; 21(5):1179-86

33. Nguyen-Tan PF, Le QT, Quivey JM, Singer M, Terris DJ, Goffinet DR, Fu KK. Treatment results and prognostic factors of advanced T3--4 laryngeal carcinoma: the University of California, san Francisco (UCSF) and Stanford University Hospital (SUH) experience. Int J Radiat Oncol Biol Phys. 2001; 50(5):1172-80.

34. Cerezo L, Millan I, Torre A, Aragon G, Otero J. Prognostic factors for survival and tumor control in cervical lymph node metastases from head and neck cancer. A multivariate study of 492 cases. Cancer. 1992;69(5):1224-34.

35. Manni JJ, Terhaard CH, de Boer MF, Croll GA, Hilgers FJ, Annyas AA, van der Meij AG, Hordijk GJ. Prognostic factors for survival in patients with T3 laryngeal carcinoma. Am J Surg. 1992;164(6):682-7.

36. Hamoir M, Schmitz S, Suarez C, Strojan P, Hutcheson KA, Rodrigo JP, Mendenhall WM, Simo R, Saba NF, D'Cruz AK, et al. The current role of salvage surgery in recurrent head and neck squamous cell carcinoma. Cancers (Basel). 2018;10(8):E267.

37. Bhide SA, Newbold KL, Harrington KJ, Nutting CM. Clinical evaluation of intensity-modulated radiotherapy for head and neck cancers. Br J Radiol. 2012;85(1013):487-94.

38. Spiotto MT, Weichselbaum RR. Comparison of 3D confromal radiotherapy and intensity modulated radiotherapy with or without simultaneous integrated boost during concurrent chemoradiation for locally advanced head and neck cancers. PLoS One. 2014;9(4):e94456.

39. Al-Mamgani A, Mehilal R, van Rooij PH, Tans L, Sewnaik A, Levendag PC. Toxicity, quality of life, and functional outcomes of 176 hypopharyngeal cancer patients treated by (chemo)radiation: the impact of treatment modality and radiation technique. Laryngoscope. 2012;122(8):1789-95.

40. Pauloski BR, Rademaker AW, Logemann JA, Discekici-Harris M, Mittal BB. Comparison of swallowing function after intensity-modulated radiation therapy and conventional radiotherapy for head and neck cancer. Head Neck. 2015;37(11):1575-82.

41. Chen AM, Hsu S, Meshman J, Chin R, Beron P, Abemayor E, St John M. Effect of daily fraction size on laryngoesophageal dysfunction after chemoradiation for squamous cell carcinomas of the larynx and hypopharynx. Head Neck. 2017;39(7):1322-6.

42. Caudell JJ, Carroll WR, Spencer SA, Bonner JA. Examination of laryngoesophageal dysfunction-free survival as an endpoint in nonsurgical treatment of squamous cell carcinomas of the larynx and hypopharynx. Cancer. 2011;117(19):4447-51.

43. Ward MC, Adelstein DJ, Bhateja P, Nwizu TI, Scharpf J, Houston N, Lamarre ED, Lorenz R, Burkey BB, Greskovich JF, et al. Severe late dysphagia and cause of death after concurrent chemoradiation for larynx cancer in patients eligible for RTOG 91-11. Oral Oncol. 2016;57:21-6.

44. Forastiere AA, Zhang Q, Weber RS, Maor MH, Goepfert H, Pajak TF, Morrison W, Glisson B, Trotti A, Ridge JA, et al. Long-term results of RTOG 91-11: a comparison of three nonsurgical treatment strategies to preserve the larynx 
in patients with locally advanced larynx cancer. J Clin Oncol. 2013;31(7): 845-52.

45. Machtay M, Moughan J, Trotti A, Garden AS, Weber RS, Cooper JS, Forastiere A, Ang KK. Factors associated with severe late toxicity after concurrent chemoradiation for locally advanced head and neck cancer: an RTOG analysis. J Clin Oncol. 2008;26(21):3582-9.

46. Furuta Y, Homma A, Oridate N, Suzuki F, Hatakeyama H, Suzuki K, Nishioka T, Shirato H, Fukuda S. Surgical complications of salvage total laryngectomy following concurrent chemoradiotherapy. Int J Clin Oncol. 2008;13(6):521-7.

47. Hasan Z, Dwivedi RC, Gunaratne DA, Virk SA, Palme CE, Riffat F. Systematic review and meta-analysis of the complications of salvage total laryngectomy. Eur J Surg Oncol. 2017;43(1):42-51.

Ready to submit your research? Choose BMC and benefit from:

- fast, convenient online submission

- thorough peer review by experienced researchers in your field

- rapid publication on acceptance

- support for research data, including large and complex data types

- gold Open Access which fosters wider collaboration and increased citations

- maximum visibility for your research: over $100 \mathrm{M}$ website views per year

At $\mathrm{BMC}$, research is always in progress.

Learn more biomedcentral.com/submissions 